public places is increasing; and even smokers are in favour of further restrictions on smoking. ASH cannot, of course, claim all the credit for this, but its constant production of high-quality information and its many initiatives such as the "butt of the month" award for outstanding services to national ill health cannot have done anything but encourage change.

Much of ASH's work has been more directly political: it wants the Government not just to ban tobacco advertising but to adopt a total antismoking strategy. This would mean, for instance, that the Government would not permit tobacco company sponsorship of sporting and cultural events; would refuse grants for building cigarette factories; would encourage insurance companies to offer lower life insurance premiums to non-smokers; and would discourage the activities of tobacco companies in the Third World. Advertising, however, has been the main issue of the past decade. ASH argues that only a combination of a total ban on advertising and other Government programmes against smoking can have the necessary impact. Evidence from Norway and Finland, both of which have enacted comprehensive antismoking legislation, shows that smoking has fallen in both countries since the Acts were passed. Most encouraging are the figures that show that $19 \%$ of Finnish 14-year-olds smoked in 1973 as opposed to $8 \%$ in 1979, one year after the Act.

Sponsoring full-scale research has been beyond the budget of ASH, but it has made new contributions to knowledge about smoking. It has used opinion polls to show that smokers tend to underestimate severely the risk they incur from smoking. In 1975 another survey commissioned by $\mathrm{ASH}$ showed that over $80 \%$ of tobacconists were selling cigarettes to under-age children. Last year ASH set up a research committee to identify gaps in knowledge about smoking, and already it has made suggestions for further studies.

Where should ASH go now ? Essentially it must continue to do more of what it does already; even if the Holy Grail of a Government doing its utmost to stop smoking is achieved there will still be a role for ASH-researching, providing accurate information, and working with individuals. More likely in the short term, however, is a Government policy that is halfheartedly antismoking-one that bans advertising but permits sponsorship, for instance-and so ASH's political activities will have to continue. One line that ASH has not as yet pursued with all its energy is the campaign to increase the amount of smoke-free space in places of work, pubs, restaurants, and any public place. Up until now the policy of always arguing from solid evidence has restricted their campaign, but the recent major paper showing increased mortality from lung cancer in non-smokers passively exposed to tobacco smoke (17 January, p 183) must give ASH the ammunition it needs. There is now no excuse for British Rail to persist with carriages that are half smoking and half non-smoking, and the British Airports Authority should be compelled to stop people smoking in non-smoking areas. Also the Health and Safety Executive, which has been slow to give advice on limiting smoking in the workplace, should begin to act on this issue.

Over the last 150 years doctors have played prominent parts in several major preventive health campaigns-for better sanitation, cleaner air, and cleaner water, for instance-but the fight against smoking has proved one of the most bitter. There are, however, equally difficult battles ahead; and one which will be closely analogous to ASH's campaign will be that to limit the damage done to the public health by alcohol. Those arming themselves for these struggles can learn a great deal by studying the activities of ASH.

\section{Co-ordination of trials in breast cancer}

In 1977 a committee was set up to co-ordinate trials of treatment of breast cancer, working under the auspices of the Cancer Research Campaign, the Medical Research Council, and the Imperial Cancer Research Fund. ${ }^{1}$ Its main aims were to promote co-ordination and collaboration among those centres conducting breast cancer trials; to disseminate information; and to establish formal links with other bodies with similar aims in Europe and North America. Since then, the committee has been formally adopted as a subcommittee of the Co-ordinating Committee on Cancer Research, which in turn facilitates the exchange of information among the Cancer Research Campaign, Medical Research Council, and Imperial Cancer Research Fund.

The Breast Cancer Trials Co-ordinating Subcommittee has recently issued its first news bulletin. ${ }^{2}$ Its activities have included a series of minisymposia on the organisation of trials, the management of preinvasive cancer and premalignant change, and proposals for a trial of local management by primary radiotherapy alone.

The subcommittee reports considerable variation in the structure of those centres conducting trials, which may be organised on a multicentre, regional, or local basis. While generally favouring a regional organisation, the subcommittee sees its task as promoting collaboration among these trial centres, and it recognises the sense of building on an existing structure. It does not see the need to establish a central dataprocessing unit, such as in the centre in Brussels run by the European Organisation for Research on the Treatment of Cancer.

The subcommittee arranged a discussion between surgical and pathological representatives of the four major centres participating in the national study of the effectiveness of screening for breast cancer (Edinburgh, Guildford, Huddersfield, and Nottingham). This was concerned with the management of in-situ non-invasive malignant and premalignant lesions of the breast-which should now be being discovered by mammographic screening. The subcommittee found considerable variation in the methods of management, varying from local excision of the lesion to bilateral mastectomy. A controlled trial comparing mastectomy with local excision would be of interest, but a review of likely numbers indicated that this would not be feasible. Long-term follow-up studies are needed to define the clinical course of these conditions.

"Breast conservation"- the treatment of breast cancer by local excision and primary radiotherapy-is now being practised in several centres. The subcommittee considers that a random comparison of this method of treatment with orthodox mastectomy is urgently needed, and meetings have been arranged with those co-ordinating major trials to look at the possibility of a national collaborative study. The news bulletin emphasises the importance of obtaining oestrogen receptor assays in all breast cancers, a task which few laboratories in Britain are able reliably to perform. It also gives future plans for the assessment of the morbidity from chemotherapy and radiotherapy.

Much of the bulletin is taken up with a review of existing trials, which is a sequel to the paper published in the $B M \mathcal{F}^{3}{ }^{3}$ Many of the smaller studies then reported have now been discontinued. Currently, in Britain there are 3791 patients in trials still in progress and 11571 being followed up in closed trials. Even though this is a small proportion of the total 
number of patients with breast cancer, these are impressive figures. If the subcommittee can achieve its aims and institute a new generation of large collaborative trials continuing assessment will have become an accepted part of the treatment of breast cancer. Controlled therapeutic trials will not discover a cure; but they are an essential part of the assessment of new methods of treatment, and they spare women the potential morbidity of unsuitable and untried methods of treatment.

1 Anonymous. Systemic chemotherapy for primary breast cancer. $\mathrm{Br} \mathrm{Med} \mathcal{F}$ $1977 ; \mathrm{i}: 336-7$.

${ }^{2}$ Cancer Trial Co-ordinating Subcommittee. News Bulletin. Edinburgh: BCTCS, 1980: No 1 .

3 Co-ordinating Committee. Clinical trials of the treatment of breast cancer in Britain and Ireland. Br Med F 1977;i:361-4.

\section{Cardiac surgery in infancy}

Some congenital heart lesions may be found in about eight per 1000 live births. ${ }^{1-3}$ Of these, nearly one-third are ventricular septal defects. Seven other lesions-atrial septal defect, patent ductus arteriosus, coarctation of aorta, aortic and pulmonary stenosis, Fallot's tetralogy, and transposition of the great arteries-among them account for a further $50 \%$. Many of these lesions, such as small atrial and ventricular septal defects, carry an excellent prognosis. Others, such as transposition, are fatal. Most deaths from congenital heart disease occur within the first year of life, most of them within the first month. Transposition, ventricular septal defect, coarctation, and the varieties of left heart hypoplasia are responsible for half the deaths. These facts of infant life explain how many children can develop normally despite having congenital heart disease, but others, usually with more complex and less common lesions, will not survive without surgical treatment, which must be undertaken early if it is to be successful.

The surgical treatment of congenital heart disease may be palliative or "corrective." The technical problems of operating on infants led to the development of a number of lifesaving and relatively simple palliative procedures, such as the Blalock shunt (in which the subclavian artery is anastomosed to the pulmonary artery, thereby increasing the blood supply to the lungs and improving system arterial oxygenation); banding of the pulmonary artery to diminish pulmonary blood flow in infants with large left-to-right shunts; and atrial septostomy to increase systemic and pulmonary venous mixing in transposition. "Corrective" procedures may either be simple and truly corrective, such as the ligation of a patent ductus arteriosus, or may be corrective in the sense that they restore the circulation towards normal without correcting the anatomical fault, as in the Mustard operation for transposition, in which an atrial baffle is constructed to redirect the venous blood into the appropriate ventricle and arterial system.

How good are the results of surgery in infancy? A recent paper $^{4}$ from the Hospital for Sick Children, Great Ormond Street, London, has looked at the survivors of cardiac surgery on 599 infants between 1955 and 1976. The outcome was determined by the risk of the operative procedure and its efficacy. Primary closure of ventricular septal defect gave both a low initial mortality and a high late survival rate. Relief of pulmonary stenosis and aortic coarctation and correction of total anomalous pulmonary venous drainage all carried a high initial mortality but gave a high late survival rate. Mustard's operation and shunts for Fallot's tetralogy resulted in a low initial mortality but low late survival rate. Pulmonary artery banding for ventricular septal defect or transposition, shunts for pulmonary atresia with ventricular septal defect, and atrial septostomy for transposition all resulted in low initial and low late survival rates.

This study reflects the increasing emphasis and success of cardiac surgery in infancy (320 open heart operations were performed in Britain in children aged under 1 year in 1978), and provides evidence against which future developments can be compared. One conclusion drawn from the study is that two-stage procedures-palliation in infancy followed by correction later-give unsatisfactory results: the low overall survival from pulmonary artery banding should mean that this procedure has limited application in the future.

A trend towards primary correction of congenital heart disease is also described in a study from San Francisco of 509 infants operated on between 1975 and $1979 . .^{5}$ Conventional palliative procedures were necessary for only about $5 \%$ of infants with more complex lesions, and some $84 \%$ underwent corrective procedures. Though there are exceptions to this trend-for example, small babies with Fallot's tetralogy and hypoplastic pulmonary arteries 6 -infants requiring surgery for congenital heart disease should be offered corrective procedures whenever possible.

${ }^{1}$ Campbell $M$. Incidence of cardiac malformations at birth and later, and neonatal mortality. Br Heart f 1973;35:189-200.

${ }^{2}$ Mitchell SC, Korones SB, Berendes HW. Congenital heart disease in 56109 births : incidence and natural history. Circulation 1971;43:323-32.

${ }^{3}$ Keith JD, Rowe RD, Vlad P. Heart disease in infancy and childhood. 2nd ed. London: Macmillan, 1967.

${ }^{4}$ Macartney FJ, Taylor JFN, Graham GR, De Leval M, Stark J. The fate of survivors of cardiac surgery in infancy. Circulation 1980;62:80-91.

${ }^{5}$ Turley K, Tucker WY, Ebert PA. The changing role of palliative procedures in the treatment of infants with congenital heart disease. f Thorac Cardiovasc Surg 1980;79:194-201.

${ }^{6}$ Kirklin JW, Blackstone EH, Pacifico AD, Brown RN, Bargeron LM. Routine primary repair vs two-stage repair of tetralogy of Fallot. Circulation 1979;60:373-86.

\section{Hunting rare adverse drug reactions}

Adverse reactions that occur in an incidence of about 1 in a 100 are likely to be detected in the premarketing tests of a new drug. Nevertheless, less common adverse reactions and those that occur in patients not included in premarketing studiespregnant women, for instance-often cannot be detected before marketing. The public, doctors, the drug industry, and the media all remember painfully the problems encountered with thalidomide and practolol, and there is strong pressure for adverse reactions to be detected as quickly and efficiently as possible. Hence various drug companies have tried systems of "monitored release," where doctors are encouraged by the company to report adverse reactions of new drugs, but these have not been successful and sometimes have come dangerously close to being disguised promotion.

In the last few months three new schemes have been mooted. The Government's scheme, Retrospective Assessment of Drug Safety (RADS), has been abandoned for economic reasons. The Royal College of General Practitioners' scheme, where drug companies commission a study of a new drug, has been 